\title{
Article \\ F127/Cisplatin Microemulsions: In Vitro, In Vivo and Computational Studies
}

\author{
Saman Sargazi $^{1}\left(\mathbb{D}\right.$, Mohammad Reza Hajinezhad $^{2}$, Mahmood Barani $^{3} \mathbb{D}$, Mahwash Mukhtar $^{4} \mathbb{D}^{(}$, \\ Abbas Rahdar ${ }^{5, *(\mathbb{D})}$, Francesco Baino ${ }^{6, *(\mathbb{D})}$, Pouya Karimi ${ }^{7}$ and Sadanand Pandey ${ }^{8,9}$ (D)
}

1 Cellular and Molecular Research Center, Resistant Tuberculosis Institute, Zahedan University of Medical Sciences, Zahedan 98167-43463, Iran; sgz.biomed@gmail.com

2 Basic Veterinary Science Department, Veterinary medicine Faculty, University of Zabol, Zabol 98613-35856, Iran; hajinezhad@uoz.ac.ir

3 Department of Chemistry, Shahid Bahonar University of Kerman, Kerman 76169-14111, Iran; mahmoodbarani7@gmail.com

4 Faculty of Pharmacy, Institute of Pharmaceutical Technology and Regulatory Affairs, University of Szeged, 6720 Szeged, Hungary; mukhtar.mahwash@pharm.u-szeged.hu

5 Department of Physics, University of Zabol, Zabol 98613-35856, Iran

6 Institute of Materials Physics and Engineering, Applied Science and Technology Department, Politecnico di Torino, Corso Duca degli Abruzzi 24, 10129 Torino, Italy

7 Department of Chemistry, Faculty of Science, University of Zabol, Zabol 98615-538, Iran; pkarimi@uoz.ac.ir

8 Particulate Matter Research Center, Research Institute of Industrial Science \& Technology (RIST), 187-12, Geumho-ro, Jeollanam-do, Gwangyang-si 57801, Korea; sadanand.au@gmail.com

9 Department of Chemistry, College of Natural Science, Yeungnam University, 280 Daehak-Ro, Gyeongbuk, Gyeongsan 38541, Korea

* Correspondence: a.rahdar@uoz.ac.ir (A.R.); francesco.baino@polito.it (F.B.)

Citation: Sargazi, S.; Hajinezhad, M.R.; Barani, M.; Mukhtar, M.; Rahdar, A.; Baino, F.; Karimi, P.; Pandey, S. F127/Cisplatin

Microemulsions: In Vitro, In Vivo and Computational Studies. Appl. Sci. 2021, 11, 3006. https://doi.org/ 10.3390/app11073006

Received: 6 March 2021

Accepted: 24 March 2021

Published: 27 March 2021

Publisher's Note: MDPI stays neutral with regard to jurisdictional claims in published maps and institutional affiliations.

Copyright: (c) 2021 by the authors. Licensee MDPI, Basel, Switzerland. This article is an open access article distributed under the terms and conditions of the Creative Commons Attribution (CC BY) license (https:/ / creativecommons.org/licenses/by/ $4.0 /)$.

\begin{abstract}
The development of effective strategies for local administration of chemotherapeutic drugs, thus minimizing the adverse side effects to patients, is one of the key challenges in biomedicine and cancer research. This work reports the formulation and characterization of PluronicF127 microemulsions to enhance the bioavailability of Cisplatin (Cis). The size of Cis microemulsion was about $12.0 \mathrm{~nm}$, as assessed by dynamic light scattering analysis. In vitro cytotoxic activity of free Cis and F127/Cis microemulsions were studied on malignant (C152 and MCF7) and normal (HUVEC) cells via tetrazolium (MTT) colorimetric assay. Cell morphology was also monitored. In vitro assessments revealed thatF127/Cis microemulsions induced cytotoxicity/morphological changes to a lesser extent than free Cis. Regarding in vivo experiments, F127/Cis microemulsions were injected intraperitoneally at 7 and $14 \mathrm{mg} / \mathrm{kg}$ doses into adult male Wistar rats to assess histologic and biochemical changes. In this case, the bulk Cis group caused severe histopathological changes and significant increases in serum liver enzymes and serum kidney function markers. The group treated with the $14 \mathrm{mg} / \mathrm{kg}$ dose of F127/Cis microemulsions also showed severe fatty changes and significant increases in serum liver enzymes, blood urea nitrogen, and creatinine levels. The group treated with the low dose of nano-Cis showed a significant increase in serum liver enzymes levels accompanied by mild fatty changes of the liver. Theoretical surveys were performed to get an understanding of the interplay between F127 and Cis. Results reveal that hydrogen bonding (HB) interactions with F127have an influence on the molecular properties of Cis and may playa role in the lower toxicity of F127/Cis in comparison to free Cis.
\end{abstract}

Keywords: Biomaterials; polymers; Nanomaterials; in vitro; cytotoxicity; cancer treatment; drug delivery systems

\section{Introduction}

Cisdiamminedichloroplatinum (II), commonly known as Cisplatin (Cis), is a platinum coordinate compound that is highly soluble in water and soluble in N,N-dimethylformamide, 
and dimethylprimanide [1]. It acquired FDA approval in 1978 for the treatment of testicular and ovarian cancer. It also holds the potential for the treatment of lung, ovarian, and breast cancers [2,3], and it has recently being explored for the treatment of bladder cancer [3,4]. Cis has been extensively used in clinical studies, but the mechanism of internalization in cancer cells remains ambiguous. The existing studies, however, demonstrate that $\mathrm{Cis}$ is taken up by the cells via passive diffusion, or the CTR1 cell membrane protein aids in the Cis influx [5]. Cis has a partition coefficient $\left(\log P_{\text {octanol/water }}\right)$ value of -2.19 , making it a hydrophilic molecule; therefore, it has reduced permeation across the biological membranes and reduced retention [6]. Thus, despite its clinical advantages, Cis suffers from low bioavailability, rapid blood clearance, and severe nephrotoxicity. Moreover, multi-drug resistance (MDR) is developed by the cancer cells due to prolonged treatment and is one of the major causes of the failure of chemotherapy [7]. The traditional chemotherapeutic drug delivery approaches suffer from the off-site drug accumulation at the desired site. This often leads to organ toxicity [8].

As a result of recent advances in nanomedicine, the drug accumulation/confinement may be improved at the target site with the possibility of the controlled release of the drug in the tumor matrix or cells, thus reducing the dose-dependent nephrotoxicity. Moreover, the nanocarriers are accumulated in the cancer cells via the enhanced permeability and retention effect (EPR), thereby increasing the chemotherapeutic activity [9]. Thereupon, nanotechnology-based approaches effectively entrap the drug and improve the pharmacokinetic profile of the drug as well as its biodistribution profile. Microemulsion technology is extensively used because of the thermodynamic stability and the reduced particle size of the colloid system, which allows the encapsulation of hydrophilic and hydrophobic moieties. Moreover, microemulsions improve the stability and bioavailability of drugs and can also solubilize drugs of a different nature [10].

Some special types of microemulsions, being responsive to certain stimuli, such as $\mathrm{pH}$, temperature, light, or magnetic fields [11], can also be conceived as intelligent nanorobots, opening fascinating horizons in many industries and research fields, including drug release. In fact, controlling the microemulsion breaking can be a valuable strategy to finely modulate the drug delivery process in terms of both time (release kinetics) and space (release location).

Microemulsions are usually composed of water, oil, a surfactant, drug, and a cosurfactant and are characterized as oil in water $(\mathrm{O} / \mathrm{W})$, water in oil $(\mathrm{W} / \mathrm{O})$, and bicontinuous systems [12]. $\mathrm{O} / \mathrm{W}$ microemulsions are advantageous as the continuous phase is water and, hence, they are easy to scale-up towards an industrial level [13].

Several factors must be considered, such as selected oil, surfactant, and co-surfactant to optimize the drug encapsulation. In microemulsions, surfactants minimize the hydrophobic interactions between the phases to maintain stability [14]. The microemulsions composed of non-ionic surfactants hold technological versatility as such nanosystems offer stability and protection to the entrapped drug from the tumor or cancer microenvironment, along with physiological conditions of the body [15]. Moreover, their use in pharmaceutical formulations has been approved by the regulatory authorities [16]. Pluronics are triblock copolymers with the general structure (polyethylene glycol)-block-(polypropylene glycol)block-(polyethylene glycol). Pluronic F127 is a non-ionic surfactant with amphiphilic properties and is widely used in the development of microemulsions because of its biocompatibility and pronounced effect on the sustained release of drugs [17]. The use of F127 significantly improves the colloidal stability as compared to conventional ionic surfactants $[18,19]$.The molecular structures of cisplatin and F127 are shown in Scheme 1. 


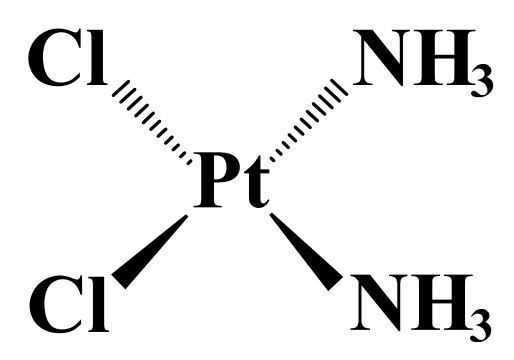

Cisplatin

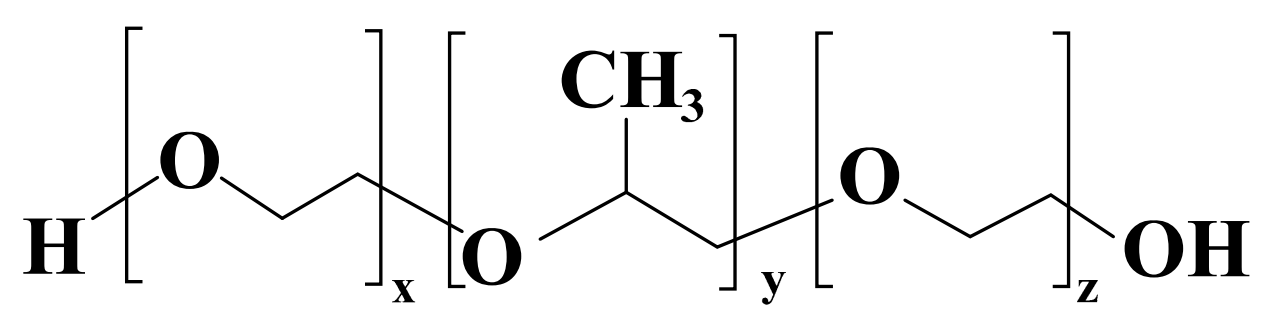

Pluronic F-127

Scheme 1. Molecular structures of cisplatin and F127.

In the earliest investigations, Cis-loaded nanocarriers were developed using polymeric or lipid structures. Recently, the reverse microemulsion method was employed to synthesize the Cis nanoparticles, later coated with lipids that improved the anti-cancer effect of Cis [20]. A self-microemulsion drug delivery system incorporating Cis has also been studied recently [21]. Similarly, lipid-based nanosystems of Cis have been developed in the past to improve anti-tumor activity [22,23]. All the previous findings focused on improving the anti-cancer activity of Cis; however, a simpler method needed to be developed that could be practically implemented, not only in technological but also in biological terms.

Thus, the main aim of this study was the development of Cis-incorporated microemulsions by a simpler technique for improving the bioavailability of Cis. The microemulsion improved the loading efficiency of the drug and hence the therapeutic effect. Altogether, the present study mainly emphasized the toxicity of the microemulsion to improve the safety profile of Cis. Moreover, the biological effect of Cis-loaded microemulsions was also elucidated.

\section{Material \& Methods}

\subsection{Chemicals, Cell Lines, and Culture Conditions}

Standard laboratory grade chemicals, including Cis, sodium caprylate,3-(4, 5-dimethylthiazol-2-yl)-2, 5-diphenyltetrazolium bromide(MTT),dimethyl sulfoxide(DMSO), phosphate-buffered saline (PBS) tablets, and ethyl butyrate, were provided by Sigma Chemical Co. Pluronic surfactant F127 was procured from BASF Inc. (Mount Olive, NJ, USA). Fetal bovine serum (FBS), RPMI1640, Debucco's modified eagle medium (DMEM), and 1\% antibiotic-antimycotic solution were purchased from Inoclon (Tehran, Iran).The human cancer cell lines (MCF7 derived from breast tumor and C152 derived from squamous cells of oral carcinoma) were obtained from the National Cell Bank of Iran, Pasteur Institute of Iran, and were grown in RPMI 1640 and DMEM culture mediums, respectively. The HUVECs were kindly provided by Dr. Roghayeh Sheervalilou (Zahedan University of Medical Science, Zahedan, Iran) and cultured in DMEM medium. Culture mediums were supplemented with $10 \%$ heat-deactivated FBS, antibiotics $(50 \mathrm{U} / \mathrm{mL}$ of penicillin and 
$50 \mu \mathrm{g} / \mathrm{mL}$ of streptomycin), and antimycotic $(250 \mu \mathrm{g} / \mathrm{mL}$ of amphotericin). Cells were sub-cultured in $25 \mathrm{~cm}^{2}$ flasks and maintained in a humidified atmosphere $(95 \%$ air, $5 \%$ $\left.\mathrm{CO}_{2}\right)$ at $37^{\circ} \mathrm{C}$.

\subsection{Formulation of Cis-Incorporated Microemulsions}

The synthesis of Cis microemulsionswas prepared using solutions of ethyl butyrate by vigorously stirring (for $24 \mathrm{~h}$ ) the required amounts of F127, PBS at pH 7.4 at a fixed oil-to-surfactant molar ratio [24]. The entire microemulsion preparation procedure was executed at room temperature.

\subsection{Characterization of Cis-Loaded Microemulsions by Dynamic Light Scattering (DLS)}

DLS characterization of Cis-incorporated microemulsions was carried out using an ALV-5000F Goniometer (Germany) System coupled with a diode-pumped solid-state laser to supply polarized incident light. The system was also integrated with a digital correlator (ALV SP-86) with a sample range of $25 \mathrm{~ns}$ to $100 \mathrm{~ms}$. DLS was carried out at an angle of $\theta=90^{\circ}$ to the incident ray by calibrating the intensity scale by toluene against scattering. Hydrodynamic diameter of microemulsions calculated based on Dynamic Light Scattering theory [25-27].

\subsection{Cytotoxicity and Morphology Evaluations}

Cells $\left(5 \times 10^{3}\right.$ cells / well) were seeded in 96-well plates and incubated for $24 \mathrm{~h}$ to attach the bottom of the plates. Next, increasing concentrations of free Cis or F127/Cis microemulsions were added to the plates and incubated at $37^{\circ} \mathrm{C}$ for $48 \mathrm{~h}$. At the end of the incubation, the supernatant was removed, $200 \mu \mathrm{L}$ of MTT solution $(0.5 \mathrm{mg} / \mathrm{mL})$ was placed into each well, and the plates were kept at $37^{\circ} \mathrm{C}$ for $3 \mathrm{~h}$. The MTT solution was then discarded and $200 \mu \mathrm{L}$ of DMSO was added for formazan solubilization. The absorbance was read at the wavelength of $570 \mathrm{~nm}$ using a Hitachi U-3110 spectrophotometer (Tokyo, Japan). Reading of experimental values was expressed as the percentage of viable cells and calculated as absorbance of treated cells/absorbance of untreated cells $\times 100$. For each concentration, three independent measurements were carried out. The halfmaximal inhibitory concentration $\left(\mathrm{IC}_{50}\right)$ of freeCis and $\mathrm{F} 127 / \mathrm{Cis}$ microemulsions were also calculated via GraphPad Prism software version 7.0.

The morphological changes on MCF7, C152, and HUVEC cells were monitored at 20X magnification using an inverted microscope (Olympus IX71; Olympus Corp., Tokyo, Japan) after exposing the cells to increasing concentrations of free- and nano-Cis (as described previously). Images were taken using a digital camera.

\subsection{In Vivo Experiments}

\subsubsection{Treatments and Experimental Design}

Forty male adult rats, obtained from the laboratory animal center of the University of Zabol, were used in this experimental study. The rats were housed in polycarbonate cages at room temperature $\left(21-25^{\circ} \mathrm{C}\right)$ and $12 \mathrm{~h}$ light/dark cycles. Animals were fed a standard laboratory diet produced by the Javaneh-Khorasan animal food factory. The experimental procedure was performed following the Guide for the Care and Use of Laboratory Animals (from NIH Publication No.85-23). The study protocol was also approved by the Ethical Committee of the Faculty of Veterinary Medicine, University of Zabol, Zabol, Iran (IR.UOZ.REC.1399). Rats were randomly divided into four groups, as follows: the animals in the control group received normal saline, the second group received the bulk Cis at a dose of $7 \mathrm{mg} / \mathrm{kg}$, the third group received $\mathrm{F} 127 / \mathrm{C}$ is microemulsion at a dose of $7 \mathrm{mg} / \mathrm{kg}$, and finally, the fourth group received F127/Cis microemulsion at a dose of $14 \mathrm{mg} / \mathrm{kg}$. After two weeks of intraperitoneal injections, blood samples were collected from the rats' hearts and centrifuged $(3000 \times \mathrm{rpm}$ for $5 \mathrm{~min})$. After being centrifuged, the obtained serum samples were kept at $-20^{\circ} \mathrm{C}$ until the time of analysis. 


\subsubsection{Determination of Biochemical Parameters}

At the end of the experiment, blood was obtained by conventional methods and was immediately centrifuged $(3000 \times g \mathrm{rpm}, 15 \mathrm{~min})$ to separate the serum. The serum samples were kept in a freezer $\left(-80{ }^{\circ} \mathrm{C}\right)$ until use. Serum blood urea nitrogen $(\mathrm{BUN})$, creatinine, aspartate aminotransferase (AST), and alanine aminotransferase (ALT) levels were determined byusing commercial kits (Pars Azemoon, Tehran, Iran), according to the kit instructions. Serum lactate dehydrogenase (LDH) levels were measured using the chemical colorimetric method according to the manufacturer's instructions (Pars Azmoon, Tehran, Iran). Liver lipid peroxidation levels were determined using the method described by Ohkawa et al., with minor modifications [28].

\subsubsection{Histological Examination}

In order to potentiate the biochemical investigations, liver, heart, and kidney sections were prepared and examined under a light microscope to investigate the morphological changes following exposure to microemulsions. In summary, after blood collection, animals were euthanized using the cervical dislocation method, and liver, heart, and kidney samples were removed. Livers were sliced into pieces. One part was immediately washed with the physiological saline solution and stored in a freezer $\left(-20^{\circ} \mathrm{C}\right)$ to determine malondialdehyde (MDA) content. Another part was washed by PBS and fixed with $10 \%$ buffered formalin for further histopathological processes.

\subsection{Statistical Analysis}

The statistical analysis was performed using the software program IBM-SPSS (version 20 ). The significance level was set at $p$-value $<0.05$. The test of Kolmogorov-Smirnov was used to verify the normality of data distribution. The Friedman test and one-way analysis of variance (ANOVA), followed by Tukey's posthoc test, were performed to evaluate multiple comparisons between the experimental groups.

\subsection{Quantum Mechanics Analysis}

For gaining and presenting a comprehensive assessment of the microemulsions, the mutual interactions between Cis and F127 were investigated in-depth to understand how molecular parameters may change after interactions of this drug with surfactant. All geometries were optimized at the B3LYP/Lanl2dz level of theory using the Gaussian09 program package [29]. The topological properties of electron charge densities were calculated by AIM method using AIM2000 software [30]. The population analysis was carried out by the natural bond orbital (NBO) method [31] using the NBO program put into operation in the Gaussian09 program package [32]. Interaction energy $(\Delta \mathrm{E})$ of the binary complex that formed via interaction of Cis and F127 can be calculated using the difference between energy of complex and sum of energies of the monomers Cis and F127. The binding energy $(-\Delta \mathrm{E})$ is an indication of the binding strength of drug to F127.

\section{Results and Discussion}

\subsection{Synthesis and Characterization of CisMicroemulsions}

The hydrodynamic diameter of F127/Cis microemulsions by measurement of the DLS was measured to be approximately $12.0 \pm 0.02 \mathrm{~nm}$.

\subsection{Cytotoxicity Evaluation}

The cytotoxic activity of standard and encapsulated Cis were measured in malignant MCF7 and C152 cells compared to normal HUVECs. All three cell lines were treated with 0 to $40 \mu \mathrm{g} / \mathrm{mL}$ free Cis and F127/Cis microemulsions for $48 \mathrm{~h}$. Figure 1 demonstrates the viability of the cells upon exposure to both agents as a function of concentration. Compared with untreated cells, free Cis significantly decreased the viability of MCF7 and C152 cells in a concentration-dependent manner $(p<0.05)$. The same pattern, but to a lesser extent, was observed when HUVECs were treated with increasing concentrations of free Cis. 
IC50 values for $48 \mathrm{~h}$ treatment of C152, HUVEC, and MCF7 cells with free Cis were 6.01, 22.42 , and $6.81 \mu \mathrm{g} / \mathrm{mL}$, respectively, while these values were $13.75 \mu \mathrm{g} / \mathrm{mL}$ (for C152 cells), $14.68 \mu \mathrm{g} / \mathrm{mL}$ (for MCF7 cells), and $24.27 \mu \mathrm{g} / \mathrm{mL}$ (for HUVECs) when exposed to F127/Cis microemulsions. Between the examined cell lines, C152 cells were the most susceptible to free- and encapsulated Cis.

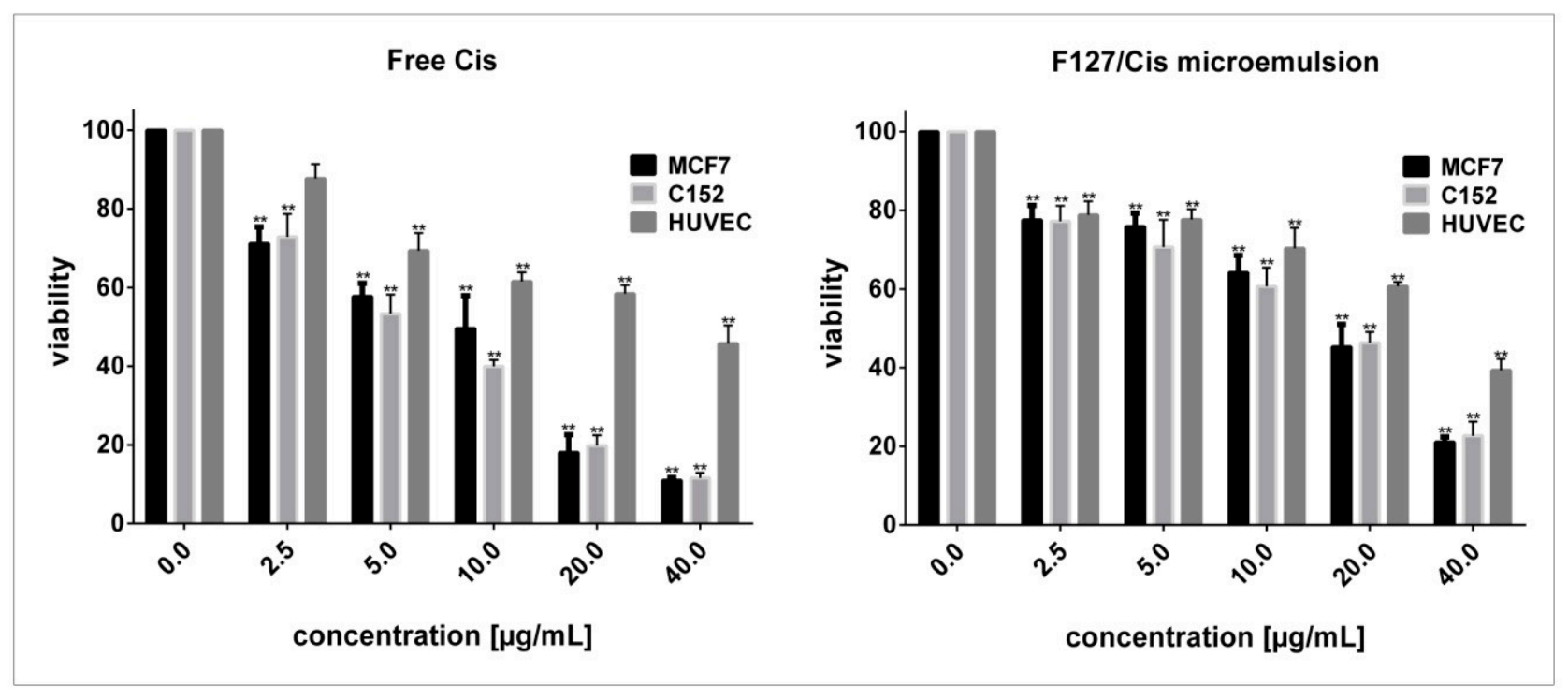

Figure 1. Cytotoxicity assessment of free Cis and F127/Cis microemulsions on malignant (MCF7 and C152) cells compared with non-malignant HUVECs following $48 \mathrm{~h}$ exposure. (** $p<0.05$ compared with untreated cells).

Based on MTT assay results, F127/Cis microemulsions induced less cytotoxic effects than free Cis on oral carcinoma cells and cancer cells derived from breast tissue (higher IC50s). Still, F127/Cis microemulsions induced less toxicity against normal HUVECs (higher IC50s), which might be a favorable outcome of using these microemulsions as an alternative tool for delivering Cis to target tissues.

All cells used as controls (without treatment) maintained an integral cellular membrane and demonstrated a uniform distribution (Figures 2 and 3). Following $48 \mathrm{~h}$ of exposure of C152 cells to free Cis at $2.5 \mu \mathrm{g} / \mathrm{mL}$, the number of viable cells was decreased. When treated with $10 \mu \mathrm{g} / \mathrm{mL}$ of free Cis, the C152 cells were morphologically rounded, and apoptotic bodies were formed. In higher concentrations of free Cis (20 and $40 \mu \mathrm{g} / \mathrm{mL}$ ), cells were detached from the culture flask. Evidently, exposure of C152 cells to nano-Cis resulted in fewer morphological changes as cells were not detached from the culture flask, and cell shrinkage and roundness were only noticed when treated with the highest concentration $(40 \mu \mathrm{g} / \mathrm{mL})$ of F127/Cismicroemulsions (Figure 3). Similar morphological alterations were observed in MCF7 cells (Figure 4). Morphological alterations induced by free and nano-Cis on HUVECs were also examined (Data not shown). At concentrations below 10 $\mu \mathrm{g} / \mathrm{mL}$ of encapsulated Cis, no evident change in HUVEC cell morphology was noticed. At concentrations between 20 and $40 \mu \mathrm{g} / \mathrm{mL}$, a mild to moderate decrease in the number of living HUVECs were observed. In contrast, free Cis at lower concentrations (5 to 10 $\mu \mathrm{g} / \mathrm{mL}$ ) induced mild changes in the morphology of HUVECs. As compared with free Cis, we observed milder morphological changes and lesser cytotoxicity when normal human cells were treated with nano-Cis, which correlated with MTT assay results. 


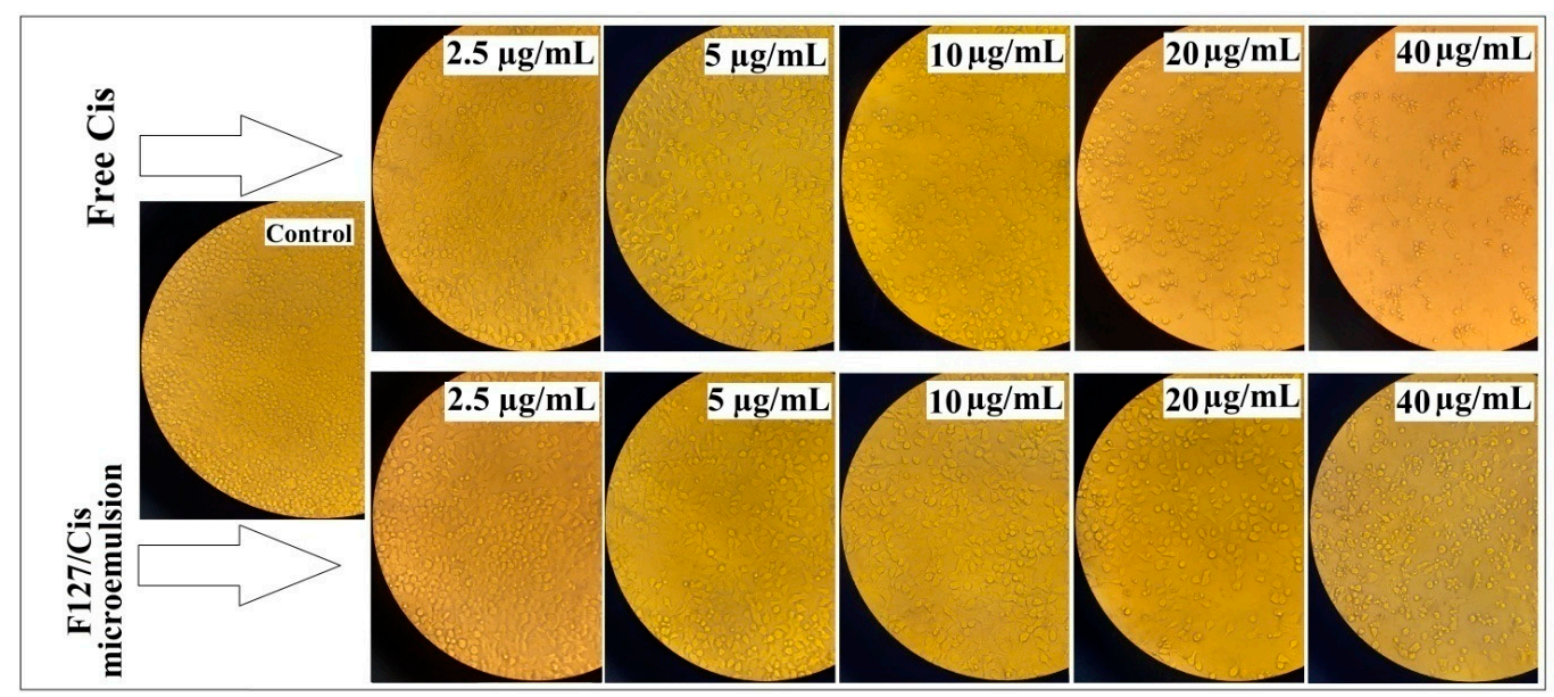

Figure 2. C152 cells exposed to 0 to $40 \mu \mathrm{g} / \mathrm{mL}$ of free Cis or F127/Cis microemulsions for $48 \mathrm{~h}$. Morphological changes of cells were visualized by invert microscopy at $20 \times$ magnification and imaged using a digital camera.

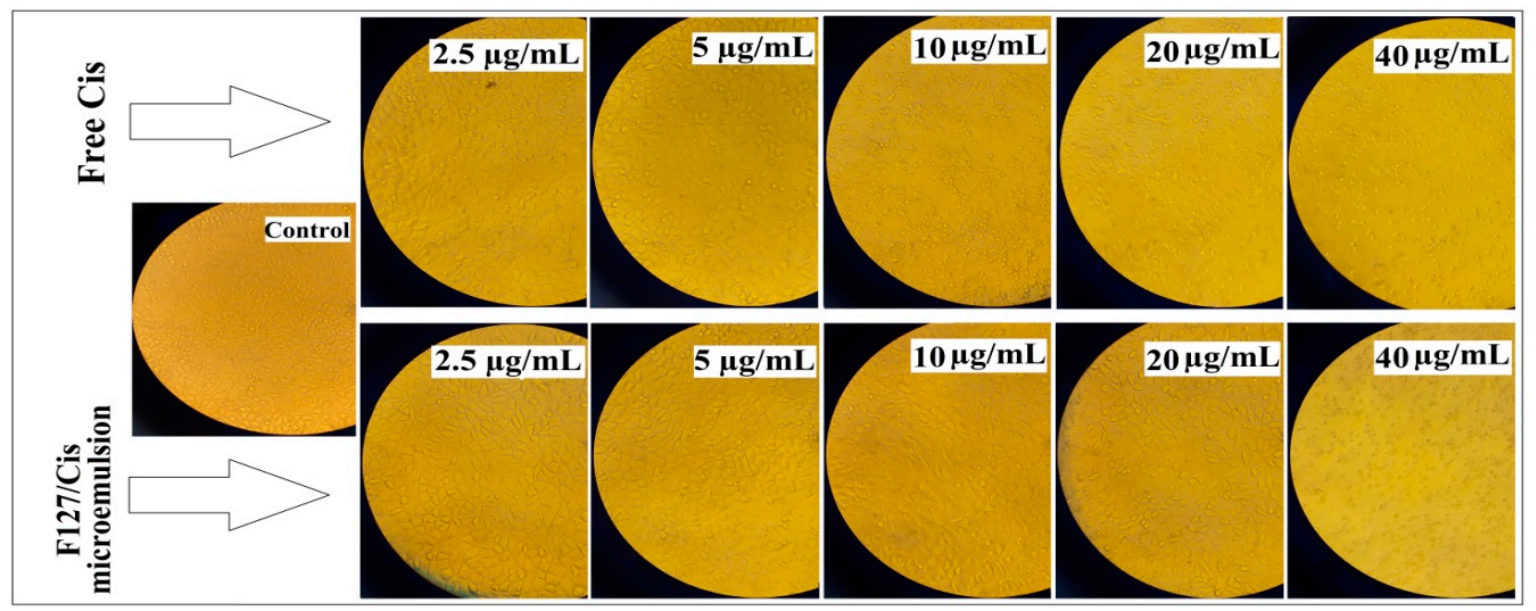

Figure 3. MCF7 cells exposed to 0 to $40 \mu \mathrm{g} / \mathrm{mL}$ of free Cis or F127/Cis microemulsions for $48 \mathrm{~h}$. Morphological changes of cells were visualized by invert microscopy at $20 \times$ magnification and imaged using a digital camera.

As a genotoxic agent, Cis is widely used alone or in combination with other antineoplastic agents/radiation as crucial first-line chemotherapy against a wide range of solid and hematological cancers [33]. However, the clinical use of free Cis is limited due to its severe organ toxicity (i.e., nephrotoxicity and peripheral neurotoxicity) [34]. Recently, researchers have attempted to improve the therapeutic efficacy of Cis while reducing its limitations and side effects [20,33]. Insolubility and uncontrolled release of Cis are the two major obstacles limiting the anti-cancer potency of the drug [35]. Guo et al. mixed two reverse microemulsions containing potassium chloride and a highly soluble precursor of Cis to formulate Cis lipid nanoparticles with controllable size. Their experiment showed promising invitro and in vivo anti-cancer activity of the synthesized nanoformulation [35]. He and his colleagues enhanced the Cis efficacy by developing biocompatible lipid-coated calcium peroxide nanoparticles, suggesting a new comprehensive therapeutic approach to be used in the challenging fight against drug-resistant cancers [20]. In a similar study in 2010, Sonoda et al. investigated Pluronic F127 for the controlled release of Cis in a rabbit model. They found that, in the presence of Pluronic, the concentration of Cis in the rabbit's kidney remained relatively high. In rabbits with liver cancer, the delivery of Pluronic F127 mixed with Cis resulted in a significantly lower tumor growth rate, compared with Pluronic F127 or Cis alone [36]. In our study, in agreement with the findings of Sonoda 
et al., less toxicity was observed following treatment of normal human cells with F127/Cis microemulsions. However, we did not find a desirable anti-cancer activity for encapsulated Cis against tumor cells derived from human breast or oral carcinoma. Further investigations are required regarding the growth-inhibitory potential of F127/Cis microemulsions against malignant cells derived from other human tissues.

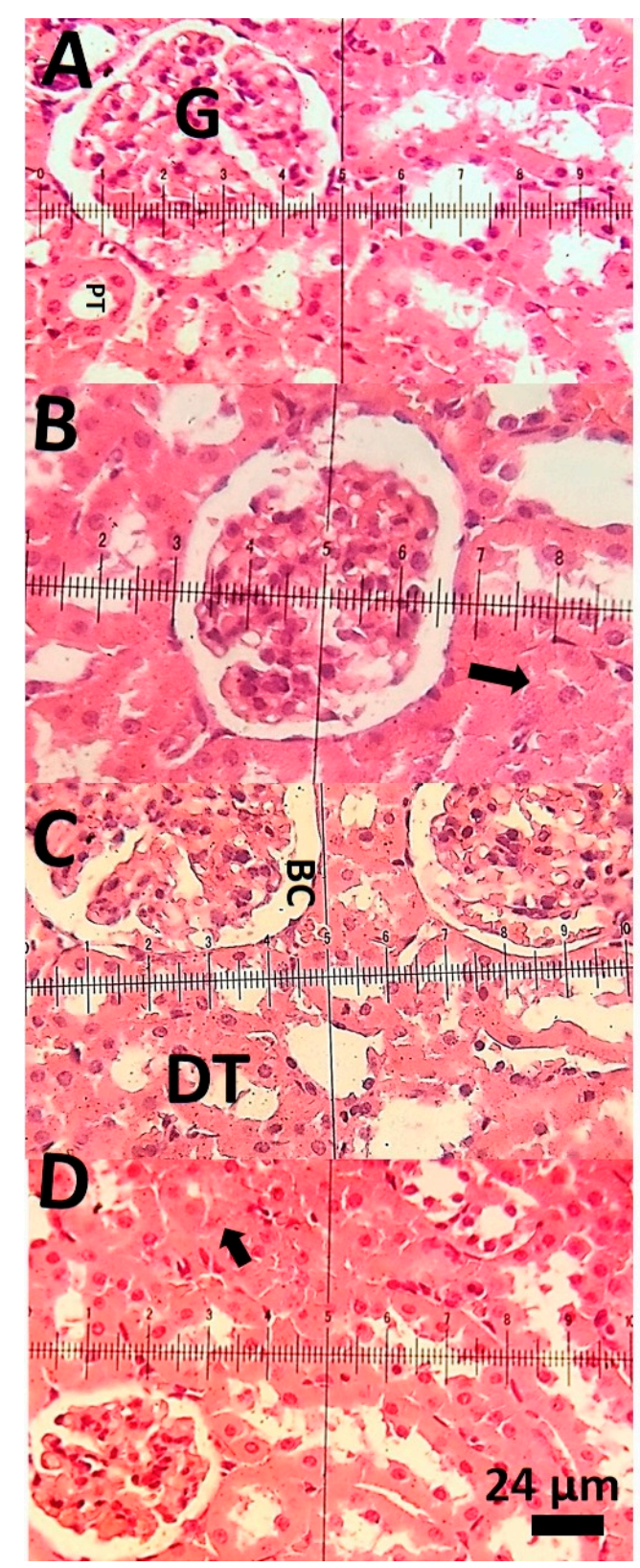

Figure 4. (A): Photomicrograph of the kidney of a control rat; normal glomerulus (G) and normal proximal tubules (PT). (B) Photomicrograph of the kidney of a rat treated with a bulk form of Cis (7 $\mathrm{mg} / \mathrm{kg}$ ); arrow shows narrowing of proximal tubules. (C) Photomicrograph of the kidney of a rat treated with F127/Cis microemulsion ( $7 \mathrm{mg} / \mathrm{kg}$ ) with normal Bowman's capsule and normal distal tubules. (D)Light micrograph of a rat's kidney treated with $14 \mathrm{mg} / \mathrm{kg}$ of F127/Cis microemulsion showing swelling of proximal tubules (arrow). (H \& E stain. Mic. Mag. $\times 40$ ).

\subsection{Biochemical Analysis}

As shown in Table 1, the group treated with the bulk form of Cis had higher serum levels of AST, ALT, and ALP compared to the control group $(p<0.001)$. Serum levels of BUN and creatinine were statistically significantly higher in rats treated with the bulk form 
of Cis than in the control rats ( $p<0.05$ and $p<0.001$, respectively). Serum LDH levels were also higher in rats treated with the bulk form of Cis compared to the controls $(p<$ 0.05 ) (Table 1). The rats that received the $7 \mathrm{mg} / \mathrm{kg}$ dose of F127/Cis microemulsion had higher serum levels of LDH, BUN, and creatinine than the healthy control group; however, these changes were not statistically significant $(p>0.05)$. The group that received the $14 \mathrm{mg} / \mathrm{kg}$ dose of F127/Cis microemulsion showed a significant increase in serum liver enzymes than the normal control group $(p<0.01)$. There was also a significant increase in serum BUN and creatinine levels in this group compared to the normal control group ( $p<0.05$ and $p<0.01$, respectively). Statistical analysis revealed a significant difference in liver malondialdehyde content of rats who received the high dose $(14 \mathrm{mg} / \mathrm{kg})$ of F127/Cis microemulsion compared to the normal control rats $(p<0.05)$. On the other hand, serum $\mathrm{LDH}$ levels did not change in rats receiving the $14 \mathrm{mg} / \mathrm{kg}$ dose of F127/Ci smicroemulsion compared to the untreated controls $(p>0.05)$. The group treated with the low dose $(7 \mathrm{mg} / \mathrm{kg})$ of F127/Cis microemulsion showed elevated levels of serum AST and ALT $(p<0.05)$; however, the other parameters remained unchanged.

Table 1. Effects of intraperitoneal injection of F127/Cis microemulsions on serum biochemical parameters and liver malondialdehyde levels. $\left({ }^{*} p<0.05\right.$ compared to control group, ${ }^{* *} p<0.01$ compared to control group, ${ }^{* * *} p<0.001$ compared to control group).

\begin{tabular}{|c|c|c|c|c|}
\hline \multirow[b]{2}{*}{ Item } & \multicolumn{4}{|c|}{ Treatment * } \\
\hline & Control & Cisplatin Bulk & $\begin{array}{c}\text { F127/Cis Microemulsion } \\
7 \mathrm{mg} / \mathrm{kg}\end{array}$ & $\begin{array}{c}\text { F127/Cis Microemulsion } \\
14 \mathrm{mg} / \mathrm{kg}\end{array}$ \\
\hline Liver MDA (nmol/mg protein) & $117.0 \pm 11.3$ & $144.9 * \pm 21.4$ & $125.8 \pm 23.4$ & $142.3 * \pm 14.2$ \\
\hline AST (U/L) & $56.8 \pm 19.4$ & $86.8^{* * *} \pm 13.3$ & $75.9 * \pm 13.5$ & $80.6^{* *} \pm 13.8$ \\
\hline $\operatorname{ALT}(\mathrm{U} / \mathrm{L})$ & $44.8 \pm 13$ & $78.9^{* * *} \pm 17.5$ & $69.6^{*} \pm 22.9$ & $71.1 * \pm 18.9$ \\
\hline $\operatorname{ALP}(\mathrm{U} / \mathrm{L})$ & $19.5 \pm 6.3$ & $38.9^{* * *} \pm 8.1$ & $25.3 \pm 6.2$ & $30.8^{* *} \pm 7.1$ \\
\hline BUN (mg/dl) & $16 \pm 4.9$ & $24.5^{*} \pm 8.7$ & $21.8 \pm 5.3$ & $23.9 * \pm 5.7$ \\
\hline Creatinine (mg/dl) & $0.71 \pm 0.11$ & $1.1^{* * *} \pm 0.21$ & $0.9 \pm 0.06$ & $1.07^{* *} \pm 0.26$ \\
\hline $\mathrm{LDH}(\mathrm{U} / \mathrm{dl})$ & $117.8 \pm 12.9$ & $134.8 * \pm 12.3$ & $118.5 \pm 5.3$ & $125.2 \pm 9$ \\
\hline
\end{tabular}

Previous experiments have shown that the nanomicelles forms of nanoparticles and drugs have better biocompatibility and biodegradability than the bulk forms of chemicals [37]. As established earlier, nanoformulations of Cis have less systemic toxicity and provide tumor-specific effects as compared with the bulk forms of Cis $[3,38]$. The anticancer and hepatotoxicity of different nanoformulations of drugs have been investigated as molecular nano-theranostic agents [39-41]. Cis encapsulation in micelles or nanoemulsions has resulted in increased therapeutic efficacy and anti-cancer efficiency [38].

\subsection{Histopathological Examinations}

Photomicrographs of the kidney of the control group showed normal glomerulus and normal proximal tubules (Figure 4A). Photomicrographs of the kidney of rats treated with the bulk form of Cis $(7 \mathrm{mg} / \mathrm{kg})$ showed narrowing of proximal tubules (Figure 4B). Rats treated with F127/Cis microemulsion $(7 \mathrm{mg} / \mathrm{kg}$ ) had normal Bowman's capsule and normal distal tubules (Figure 4C). Light micrograph of a kidney of rats treated with $14 \mathrm{mg} / \mathrm{kg}$ of F127/Cis microemulsion showed swelling of proximal tubules (Figure 4D).

Liver sections of the control group had normal hepatocytes and normal hepatic architecture (Figure 5A). Photomicrographs of the liver of rats treated with the bulk form of Cis $(7 \mathrm{mg} / \mathrm{kg}$ ) showed nuclear pyknosis (Figure 5B). In the liver of rats treated with F127/Cis microemulsion $(7 \mathrm{mg} / \mathrm{kg})$, there were normal hepatic sinusoids and mild perinuclear lipid accumulation (Figure 5C). Light micrographs of the liver of rats treated with $14 \mathrm{mg} / \mathrm{kg}$ of F127/Cis microemulsion showed severe fatty change (Figure 5D). 


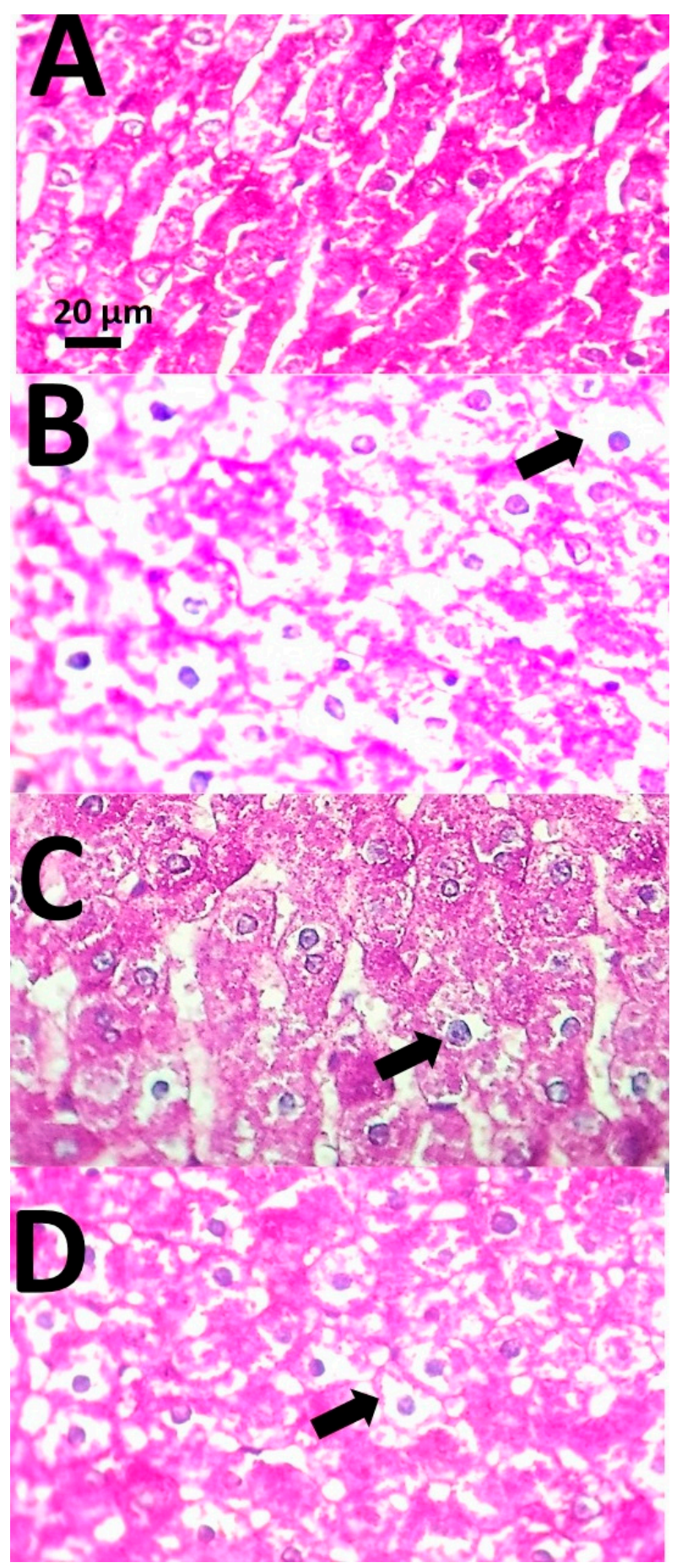

Figure 5. (A): Light micrograph of a liver section of a control rat; normal hepatocyte (arrow) and normal hepatic architecture. (B) Photomicrograph of the liver of a rat treated with a bulk form of Cis $(7 \mathrm{mg} / \mathrm{kg})$, arrow shows nuclear pyknosis. (C) Photomicrograph of the liver of a rat treated with F127/Cis microemulsion (7 mg/kg) with normal hepatic sinusoids and mild perinuclear lipid accumulation (arrow). (D) Light micrograph of a liver of a rat treated with $14 \mathrm{mg} / \mathrm{kg}$ of F127/Cis microemulsion showing severe fatty change (arrow). (Alcian blue stain. Mic. Mag. $\times 40$ ).

Heart micrographs of the control rats had normal morphology (Figure 6A). The heart section of rats treated with the bulk form of Cis $(7 \mathrm{mg} / \mathrm{kg}$ ) showed necrosis (Figure $6 \mathrm{~B}$ ). In contrast, rats treated with F127/Cis microemulsion $(7 \mathrm{mg} / \mathrm{kg}$ ) had normal heart structure 
and mild disarrangement of filamentous arrays (Figure 6C). The heart section of rats treated with $14 \mathrm{mg} / \mathrm{kg}$ of F127/Cis revealed tissue congestion (Figure 6D).

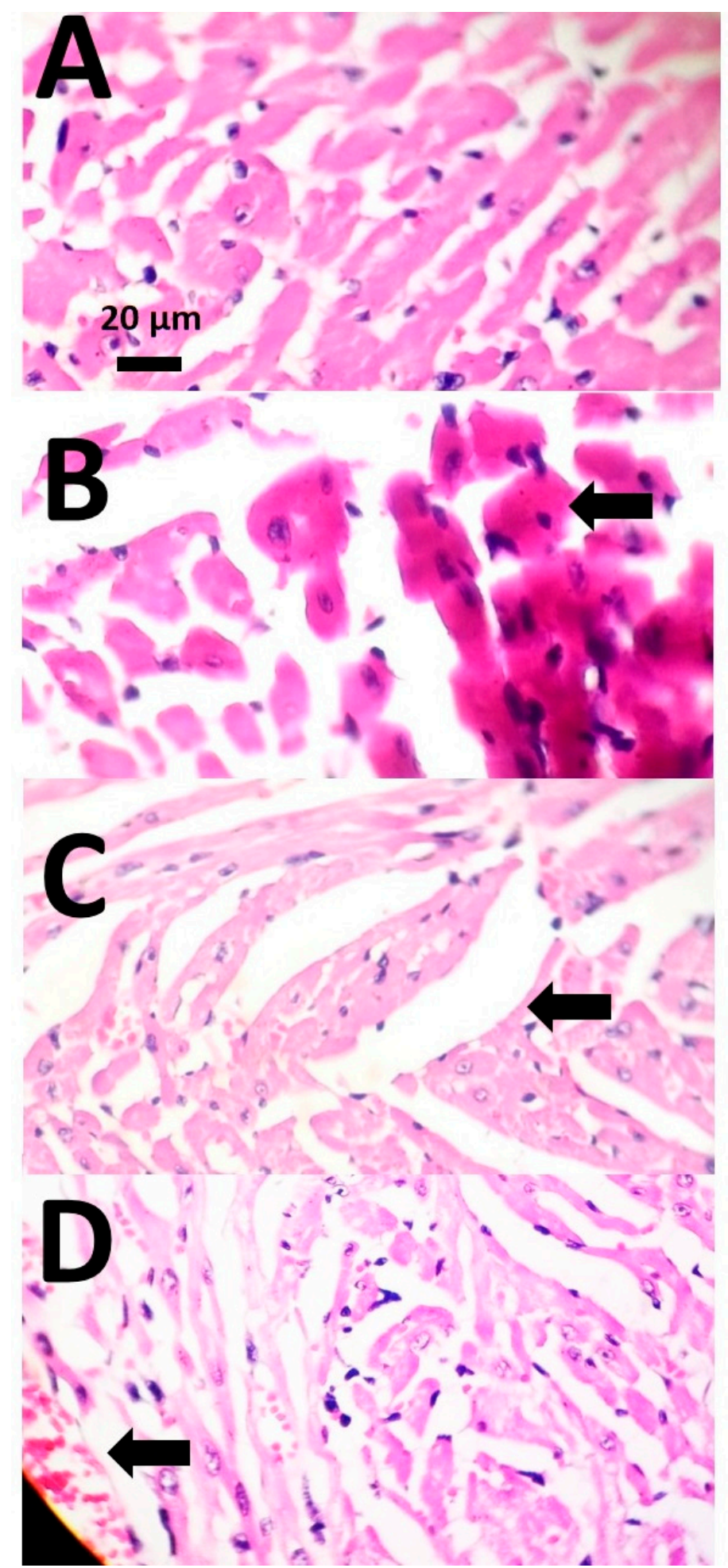

Figure 6. (A) A heart section of a control rat with normal architecture. (B) Heart section of a rat treated with a bulk form of Cis $(7 \mathrm{mg} / \mathrm{kg})$; arrow shows necrosis. (C) Photomicrograph of a rat treated with F127/Cis microemulsion $(7 \mathrm{mg} / \mathrm{kg}$ ) with normal heart structure and mild disarrangement of filamentous arrays (arrow). (D) Heart section of a rat treated with $14 \mathrm{mg} / \mathrm{kg}$ of F127/Cis microemulsion showing congestion in heart tissue (arrow). (Alcian blue stain. Mic. Mag. $\times 40$ ). 


\subsection{Computational Results: The Interplay between Cis and Surfactant F127}

As said, the clinical use of free Cis is limited due to cruel organ toxicity. Moreover, insolubility and uncontrolled release of Cis limit the anti-cancer strength of the drug. This study showed that Cis-loaded microemulsions induce less toxicity than free Cis against normal HUVEC cells. Therefore, we tried to investigate mutual interactions between Cis and F127 to understand the molecular parameters that change after interactions of this drug with surfactant.

We depicted a Molecular Electrostatic Potential (MEP) map of a unit of the polymeric chain of F127 to study the interactions of Cis with surfactant. This map helps to find electron-rich positions that are capable of hydrogen bonding $(\mathrm{HB})$ interactions with $\mathrm{Cis}$. As displayed in Figure 7, red positions are located on atoms $\mathrm{O}_{2}, \mathrm{O}_{6}$, and $\mathrm{O}_{7}$ of $\mathrm{F} 127$. Thus, we focused on these positions for $\mathrm{HB}$ interactions with Cis. Binary complexes formed via $\mathrm{HB}$ interactions of Cis with atoms $\mathrm{O}_{2}, \mathrm{O}_{6}$, and $\mathrm{O}_{7}$ of $\mathrm{F} 127$ are named $\mathbf{A}, \mathbf{B}$, and C. Results show that ammonia groups of Cis have more tendencies for $\mathrm{HB}$ interactions with $\mathrm{F} 127$ than chlorine atoms. In fact, we surveyed $\mathrm{HB}$ interactions between chlorine atoms of $\mathrm{Cis}$ and F127, but no stable complex was formed.
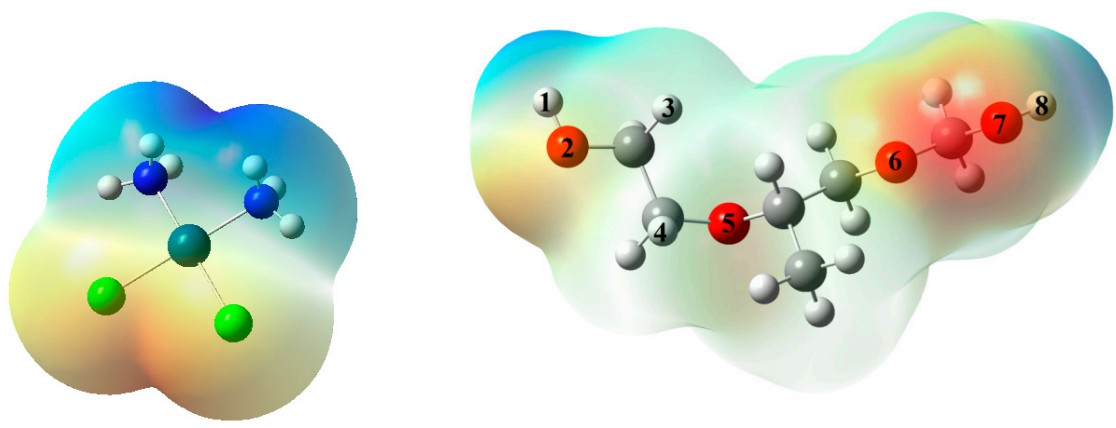

Figure 7. MEP maps of Cis (left) and F127 (right) together with numbers of important atoms.

Results indicate that the binding energy of complexes $\mathbf{A}, \mathbf{B}$, and $\mathbf{C}$, calculated at the B3LYP/Lanl2dz level of theory, is 17.21, 19.75, and $15.29 \mathrm{kcal} \mathrm{mol}^{-1}$, respectively. The hydrogen bond length $\left(\mathrm{d}_{\mathrm{NH}}\right)$ in complex $\mathbf{A}$ and $\mathbf{B}$ is 1.77 and $1.74 \AA$, respectively. On the other hand, Cis interacts through both its ammonia groups with atom $\mathrm{O}_{7}$ of F127 in the complex $\mathrm{C}$, and the average $\mathrm{d}_{\mathrm{NH}}$ value, in this case, is $2.17 \AA$. As can be seen, the increase of $\mathrm{HB}$ strength in the above-mentioned complexes is accompanied by the decrease of $\mathrm{d}_{\mathrm{NH}}$ values. This result shows that ammonia groups of Cis are good $\mathrm{HB}$ donors that interact with atoms $\mathrm{O}_{2}, \mathrm{O}_{6}$, and $\mathrm{O}_{7}$ of $\mathrm{F} 127$ as $\mathrm{HB}$ acceptors. It seems that such interplays influence the function of Cis. Therefore, we performed further computations to better understand the nature of the mentioned interplays.

The electronic properties of Cis and F127 change during the formation of the complexes. Therefore, the highest occupied molecular orbital (HOMO) and lowest unoccupied molecular orbital (LUMO) energies, and energy gap (EG) values of all geometries were calculated and are shown in Table 2.

Table 2. Energies of HOMO and LUMO, EG values (in eV), and charge of atoms involved in HB interaction (in e).

\begin{tabular}{ccccccc}
\hline & E $_{\text {HOMO }}$ & E $_{\text {LUMO }}$ & EG & qo & q & q \\
\hline Cis & -6.272 & -1.901 & 4.372 & - & 0.363 & -0.883 \\
F127 & -6.990 & 1.288 & 8.278 & $*$ & - & - \\
complex A & -6.225 & -1.739 & 4.486 & -0.567 & 0.457 & -0.916 \\
complex B & -6.383 & -1.927 & 4.455 & -0.413 & 0.463 & -0.918 \\
complex C & -6.166 & -1.711 & 4.455 & -0.548 & 0.391 & -0.890 \\
\hline
\end{tabular}

${ }^{*}$ Charge of atoms $\mathrm{O}_{2}, \mathrm{O}_{6}$, and $\mathrm{O}_{7}$ in $\mathrm{F} 127$ is $-0.494,-0.343$, and -0.458 e, respectively. 
As can be seen, the EG value of free F127 is higher than the complexes. Results indicate that a decrease of HOMO and LUMO energies is followed by the increase of the HB strength of the complexes. The lowest $\mathrm{E}_{\mathrm{HOMO}}$ and $\mathrm{E}_{\mathrm{LUMO}}$ values correspond to complex $\mathbf{B}$, with the largest binding energy value. Therefore, we have represented the distribution of HOMO and LUMO on the complexes in Figure 8. As can be observed, HOMO lays on Cis in all complexes, and there is only an extension on atom $\mathrm{O}_{6}$ of $\mathrm{F} 127$ in complex $\mathbf{B}$. Moreover, the distribution of $\mathrm{HOMO}$ on complex $\mathbf{B}$ has more $\pi$ character in comparison to other complexes. As said, this complex has the largest binding energy among other complexes. It seems that this distribution of $\mathrm{HOMO}$, which refers to division of electron charges, has an effect on the formation of stable complex $\mathbf{B}$ via HB interaction between $\mathrm{Cis}$ and atom $\mathrm{O}_{6}$ of $\mathrm{F} 127$.

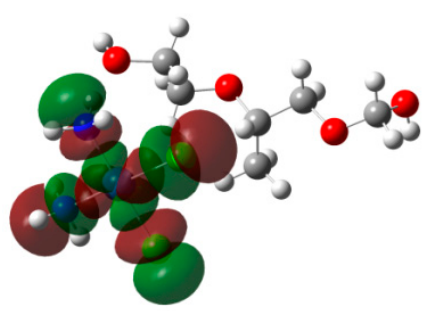

LUMO A

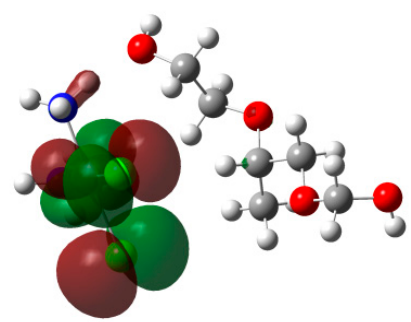

HOMO A

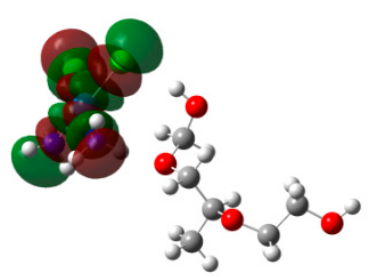

LUMO B

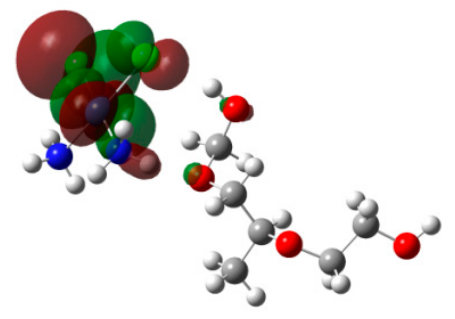

HOMO B

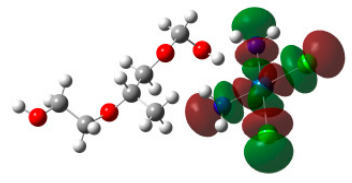

LUMO C

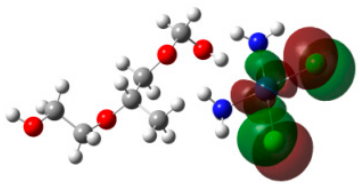

HOMO C

Figure 8. Distribution of HOMO and LUMO on the complexes.

Due to the important role of electron charge distribution on the stability of the drugsurfactant systems, it is necessary to survey atomic charges on the complexes and also free molecules Cis and F127. Results reveal that there is an overall CT in the complexes from F127 to Cis. The magnitude of negative charge that transfers to Cis is $-0.046,-0.009$, and -0.060 e in the complexes A, B, and C, respectively. As can be seen, a decrease in the absolute value of such CT is consistent with an increase in the binding energies of the complexes. Thus, as the CT diminishes, the stability of the current drug-surfactant system increases. Charges of atoms that contribute to HB interactions are presented in Table 2 and denoted with $\mathrm{q}_{\mathrm{O}}, \mathrm{q}_{\mathrm{H}}$, and $\mathrm{q}_{\mathrm{N}}$. As can be seen, $\mathrm{q}_{\mathrm{O}}$ and $\mathrm{q}_{\mathrm{N}}$ values in the corresponding complexes are more negative than those in free molecules. Additionally, the positive value of $\mathrm{q}_{\mathrm{H}}$ is amplified with complex formation. Results indicate that the sum of $\mathrm{q}_{\mathrm{O}}, \mathrm{q}_{\mathrm{H}}$, and $\mathrm{q}_{\mathrm{N}}$ has a linear relation with the stability of the complexes. The sum of mentioned charges is $-0.868,-1.026$, and -1.047 e in complexes A, B, and C, respectively. In fact, a decrease inthe sum of negative charge on atoms involved in $\mathrm{HB}$ interaction is followed by the rise 
of stability of the complexes. Moreover, an increase in the positive value of $\mathrm{q}_{\mathrm{H}}$ in the complexes is associated with the increase of such stability. This outcome highlights the role of HB donors in the formation of stable drug-surfactant systems.

Population analysis was surveyed using the NBO method to better understand electron charge transfer between molecular orbitals of $\mathrm{HB}$ donor and HB acceptor in the complexes. Thus, we calculated donor-acceptor stabilization energies $\left(\mathrm{E}^{(2)}\right.$ values) for the $\mathrm{LpO}$ to $\sigma^{*} \mathrm{NH}$ interaction. The $\mathrm{E}^{(2)}$ value for this electron charge transfer is $19.87,23.55$, and $5.74 \mathrm{kcal} \mathrm{mol}^{-1}$ in complexes A, B, and C, respectively. As can be seen, the trend of $\mathrm{E}^{(2)}$ values is the same as that of the complexes' stability. As a result, electron charge transfer from lone pair of oxygen atom (LpO) of F127 to the anti-bonding molecular orbital of $\mathrm{N}-\mathrm{H}$ $\left(\sigma^{*} \mathrm{NH}\right)$ in Cis has an effective role on the stability of the current drug-surfactant system.

Topological properties of the complexes have been planned by the AIM method. The molecular graphs involving bond critical points (BCPs) and bond paths are shown in Figure 9. As can be observed, there are two weak $\mathrm{HB}$ interactions $(\mathrm{C}-\mathrm{H} \cdots \mathrm{Cl})$ in complex $\mathbf{A}$. The electron charge density values at $\mathrm{BCPs}$ of these interactions $\left(\rho_{\mathrm{BCP}}\right)$ are $2.89 \times 10^{-3}$ and $7.50 \times 10^{-3} \mathrm{au}$. The $\rho_{\mathrm{BCP}}$ value at the main $\mathrm{HB}$ is $3.93 \times 10^{-2} \mathrm{au}$. Additionally, there are two weak HB interactions in complex $\mathrm{C}$ due to tendencies of both ammonia groups of $\mathrm{Cis}$ to atom $\mathrm{O}_{7}$ of $\mathrm{F} 127$. The $\rho_{\mathrm{BCP}}$ values related to these interactions are $1.69 \times 10^{-2}$ and 1.57 $\times 10^{-2}$ au. However, interaction in complex $\mathbf{B}$ does not include any weak $\mathrm{HB}$, and this complex has the larger binding energy. The $\rho_{\mathrm{BCP}}$ value at $\mathrm{HB}$ interaction of this complex is $4.35 \times 10^{-2}$ au. Hence, it can be suggested that the magnitudes of $\rho_{\mathrm{BCP}}$ values directly influence the complexes' stability.

We changed the concentration of drug as changed in cells to study the role of drug concentration on the thermodynamical properties of the complex formation process. Changes of thermal Gibbs free energy $(\Delta \mathrm{G})$, thermal enthalpy $(\Delta \mathrm{H})$, and thermal entropy $(\Delta S)$ are reported in Table 3. As can be seen, all $\Delta S$ values are positive, which is in agreement with spontaneous processes. Results show that an increase in drug concentration is followed by a decrease in $\Delta S$ values. In fact, irregularity decreases to some extent at higher concentrations. This outcome implies that there are positive interplays between drug and surfactant at higher concentrations. It seems that such interactions have helpful roles in decreasing the toxicity of drug-surfactant in comparison to free Cis.

Table 3. Variation of thermal Gibbs free energies, enthalpies, and entropies of the complex formation process with change of drug concentration.

\begin{tabular}{cccccc}
\hline Concentration & $\mathbf{2 . 5}$ & $\mathbf{5 . 0}$ & $\mathbf{1 0 . 0}$ & $\mathbf{2 0 . 0}$ & $\mathbf{4 0 . 0}$ \\
\hline$* \Delta \mathrm{G}$ & -3.486 & 328.313 & 988.026 & 2304.883 & 4937.124 \\
$* \Delta \mathrm{H}$ & 10.139 & 337.308 & 993.932 & 2308.857 & 4940.136 \\
$* \Delta \mathrm{S}$ & 0.046 & 0.03 & 0.020 & 0.013 & 0.010 \\
\hline \multicolumn{5}{c}{${ }^{*}$ In kcal mol ${ }^{-1}$ and $^{* *}$ in kcal mol ${ }^{-1} \mathrm{~K}^{-1 .}$} \\
\end{tabular}

Consequently, Cis forms HB interactions with electron-rich positions on F127 via its ammonia groups. Charges of atoms that take part in HB interaction between Cis and F127 influence the stability of the drug-surfactant system. Indeed, the electron charge transfers between molecular orbitals of the Cis and F127 control such stability. Formation of BCPs between HB donors and $\mathrm{HB}$ acceptors contributes to enhancing the stability of the drug-surfactant bond. Indeed, the decrease of irregularity occurs at higher concentrations of drugs, and there are acceptable interplays between Cis and F127. It seems that such intermolecular interactions may lead to less toxicity of drug-surfactant systems (i.e., microemulsions) in comparison to free Cis. 

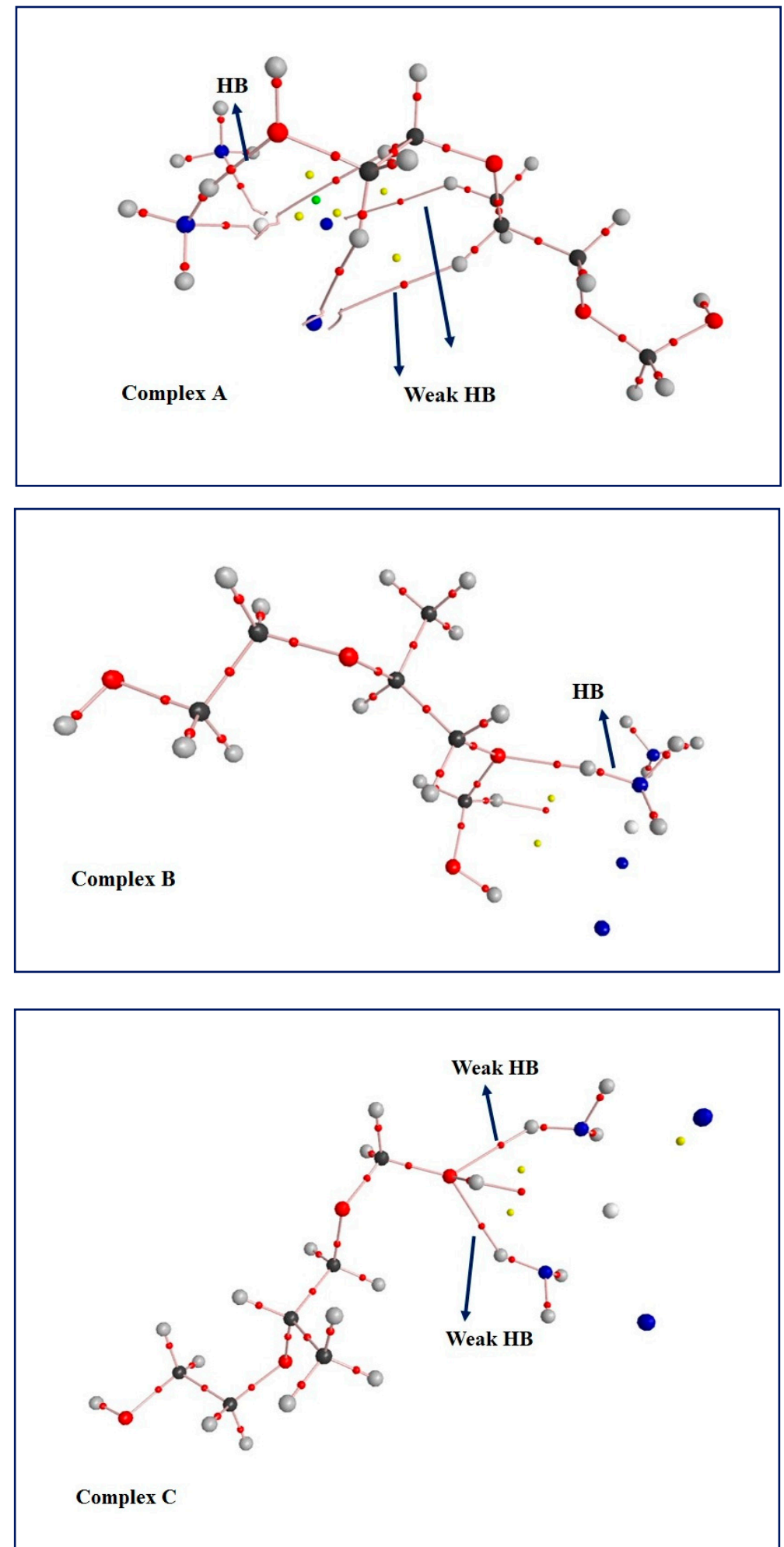

Figure 9. Presentation of molecular graphs of the complexes encompass HB interactions between drug and surfactant.

\section{Conclusions}

Our newly synthesized F127/Cis microemulsions could not induce higher cytotoxic effects than free Cis in malignant cells, suggesting that our new formulation might not be able to exert desirable cell-killing effects against cancer cells. In vivo experiments showed toxic effects of the bulk form of Cis on the liver, kidney, and heart of rats; however, the 
group treated with the low dose of F127/Cis microemulsions showed less toxic effects. Theoretical studies indicated that hydrogen bonding interactions between F127 and Cis might play a role in the lower toxicity of F127/Cis compared to free Cis. Performing more in vitro and in vivo assessments is necessary regarding the anti-cancer and/or anti-oxidant activity of F127/Cis microemulsions in human cells derived from different tissues.

Author Contributions: Conceptualization, A.R.; methodology, S.S., M.R.H., M.B., P.K., A.R. and M.M.; investigation, M.R.H., M.B., S.S., P.K., A.R. and M.B.; writing—original draft preparation, M.R.H., S.S., M.M., A.R., P.K. and M.B.; writing-review and editing, S.S., F.B., A.R. and S.P.; supervision, A.R.; All authors have read and agreed to the published version of the manuscript.

Funding: This study received funding from Zahedan University of Medical Sciences (Project. 10267).

Institutional Review Board Statement: The in vitro part of the study protocol was approved by Zahedan University of Medical Sciences (Ethical code: IR.ZAUMS.REC.1399.517). Animal handling was conducted according to the guidelines of Research Ethics Committee of University of Zabol, Zabol, Iran (Ethical code: IR.UOZ.REC.1399.009).

Informed Consent Statement: Not applicable.

Data Availability Statement: Data are included within this article.

Conflicts of Interest: The authors declare no conflict of interest.

\section{Abbreviations}

List of abbreviations used in the manuscript.

\begin{tabular}{ll}
\hline Abbreviations & Definitions \\
\hline FDA & Food and drug administration \\
Cis & Cisplatin \\
MTT & 3-( 4, 5-dimethylthiazol-2-yl)-2,5-diphenyltetrazolium bromide \\
BUN & Blood urea nitrogen \\
AST & Aspartate aminotransferase \\
ALT & Alanine aminotransferase \\
ALP & Alkaline phosphatase \\
LDH & Lactate dehydrogenase \\
MDA & Malondialdehyde \\
HB & Hydrogen bonding \\
CRT1 & Copper transporter 1 \\
MDR & Multi-drug resistance \\
EPR & Enhanced permeability and retention effect \\
O/W & Oil in water \\
W/O & Water in oil \\
DMSO & Dimethyl sulfoxide \\
FBS & Fetal bovine serum \\
PBS & Phosphate-buffered saline \\
DMEM & Dulbecco's modified Eagle's medium \\
HUVECs & Human umbilical vein endothelial cells \\
DLS & Dynamic light scattering \\
ARF & Autocorrelation function \\
MEP & Molecular electrostatic potential \\
HOMO & Highest occupied molecular orbital \\
LUMO & Lowest unoccupied molecular orbital \\
EG & Energy gap \\
CT & Charge transfer \\
BCPs & Bond critical points \\
\hline &
\end{tabular}




\section{References}

1. Dasari, S.; Tchounwou, P.B. Cisplatin in cancer therapy: Molecular mechanisms of action. Eur. J. Pharmacol. 2014, 740, 364-378. [CrossRef]

2. Ali, I.; Wani, W.A.; Saleem, K.; Haque, A. Platinum compounds: A hope for future cancer chemotherapy. Anticancer Agents Med. Chem. 2013, 13, 296-306. [CrossRef]

3. Hwang, T.-L.; Fang, C.-L.; Chen, C.-H.; Fang, J.-Y. Permeation enhancer-containing water-in-oil nanoemulsions as carriers for intravesicalcisplatin delivery. Pharm. Res. 2009, 26, 2314-2323. [CrossRef] [PubMed]

4. Taber, A.; Christensen, E.; Lamy, P.; Nordentoft, I.; Prip, F.; Lindskrog, S.V.; Birkenkamp-Demtröder, K.; Okholm, T.L.H.; Knudsen, M.; Pedersen, J.S. Molecular correlates of cisplatin-based chemotherapy response in muscle invasive bladder cancer by integrated multi-omics analysis. Nat. Commun. 2020, 11, 1-15. [CrossRef] [PubMed]

5. Ma, P.A.; Xiao, H.; Li, X.; Li, C.; Dai, Y.; Cheng, Z.; Jing, X.; Lin, J. Rational design of multifunctional upconversionnanocrystals/polymer nanocomposites for cisplatin (IV) delivery and biomedical imaging. Adv. Mater. 2013, 25, 4898-4905. [CrossRef] [PubMed]

6. Varbanov, H.; Valiahdi, S.M.; Legin, A.A.; Jakupec, M.A.; Roller, A.; Galanski, M.; Keppler, B.K. Synthesis and characterization of novel bis (carboxylato) dichloridobis (ethylamine) platinum (IV) complexes with higher cytotoxicity than cisplatin. Eur. J. Med. Chem. 2011, 46, 5456-5464. [CrossRef]

7. Domínguez-Ríos, R.; Sánchez-Ramírez, D.R.; Ruiz-Saray, K.; Oceguera-Basurto, P.E.; Almada, M.; Juárez, J.; Zepeda-Moreno, A.; del Toro-Arreola, A.; Topete, A.; Daneri-Navarro, A. Cisplatin-loaded PLGA nanoparticles for HER2 targeted ovarian cancer therapy. Colloids Surf. B Biointerfaces 2019, 178, 199-207. [CrossRef] [PubMed]

8. Yang, X.Z.; Du, X.J.; Liu, Y.; Zhu, Y.H.; Liu, Y.Z.; Li, Y.P.; Wang, J. Rational design of polyion complex nanoparticles to overcome cisplatin resistance in cancer therapy. Adv. Mater. 2014, 26, 931-936. [CrossRef]

9. Dhar, S.; Kolishetti, N.; Lippard, S.J.; Farokhzad, O.C. Targeted delivery of a cisplatinprodrug for safer and more effective prostate cancer therapy in vivo. Proc. Natl. Acad. Sci. USA 2011, 108, 1850-1855. [CrossRef] [PubMed]

10. Callender, S.P.; Mathews, J.A.; Kobernyk, K.; Wettig, S.D. Microemulsion utility in pharmaceuticals: Implications for multi-drug delivery. Int. J. Pharm. 2017, 526, 425-442. [CrossRef]

11. Zhang, Y.; Feng, Y. Stimuli-responsive microemulsions: State-of-the-art and future prospects. Curr. Opin. Colloid Interface Sci. 2020, 49, 27-41. [CrossRef]

12. Narang, A.S.; Delmarre, D.; Gao, D. Stable drug encapsulation in micelles and microemulsions. Int. J. Pharm. 2007, 345, 9-25. [CrossRef] [PubMed]

13. Sanchez-Dominguez, M.; Boutonnet, M.; Solans, C. A novel approach to metal and metal oxide nanoparticle synthesis: The oil-in-water microemulsion reaction method. J. Nanopart. Res. 2009, 11, 1823-1829. [CrossRef]

14. Biruss, B.; Valenta, C. The advantage of polymer addition to a non-ionic oil in water microemulsion for the dermal delivery of progesterone. Int. J. Pharm. 2008, 349, 269-273. [CrossRef]

15. Rahdar, A.; Hajinezhad, M.R.; Nasri, S.; Beyzaei, H.; Barani, M.; Trant, J.F. The synthesis of methotrexate-loaded F127 microemulsions and their in vivo toxicity in a rat model. J. Mol. Liq. 2020, 313, 113449. [CrossRef]

16. Rahdar, A.; Kazemi, S.; Askari, F. Pluronic as nano-carier for drug delivery systems. Nanomed. Res. J. 2018, 3, 174-179.

17. Al Khateb, K.; Ozhmukhametova, E.K.; Mussin, M.N.; Seilkhanov, S.K.; Rakhypbekov, T.K.; Lau, W.M.; Khutoryanskiy, V.V. In situ gelling systems based on Pluronic F127/Pluronic F68 formulations for ocular drug delivery. Int. J. Pharm. 2016, 502, 70-79. [CrossRef]

18. James-Smith, M.A.; Shekhawat, D.; Cheung, S.; Moudgil, B.M.; Shah, D.O. Role of ethylene oxide and propylene oxide groups of pluronics in binding of fatty acid to pluronics in microemulsions. J. Surfactants Deterg. 2008, 11, 237-242. [CrossRef]

19. Rahdar, A.; Hajinezhad, M.R.; Sargazi, S.; Bilal, M.; Barani, M.; Karimi, P.; Kyzas, G.Z. Biochemical effects of deferasirox and deferasirox-loaded nanomicellesin iron-intoxicated rats. Life Sci. 2021, 270, 119146. [CrossRef] [PubMed]

20. He, C.; Zhang, X.; Yan, R.; Zhao, P.; Chen, Y.; Li, M.; Chen, C.; Fan, T.; Lu, Y.; Wang, C. Enhancement of cisplatin efficacy by lipid-CaO 2 nanocarrier-mediated comprehensive modulation of the tumor microenvironment. Biomater. Sci. 2019, 7, 4260-4272. [CrossRef]

21. Akartas, I.; Karasulu, H.Y. Preparation and characterization of self-microemusifying drug delivery system (SMEDDS) of cisplatin for oral use in ovarian cancer treatment. Acta Pol. Pharm. Drug Res. 2020, 77, 183-193. [CrossRef]

22. Raut, I.D.; Doijad, R.C.; Mohite, S.K.; Manjappa, A.S. Preparation and Characterization of Solid Lipid Nanoparticles Loaded with Cisplatin. J. Drug Deliv. Ther. 2018, 8, 125-131. [CrossRef]

23. Zhai, Q.; Li, H.; Song, Y.; Wu, R.; Tang, C.; Ma, X.; Liu, Z.; Peng, J.; Zhang, J.; Tang, Z. Preparation and optimization lipid nanocapsules to enhance the antitumor efficacy of cisplatin in hepatocellular carcinoma HepG2 cells. AAPS PharmSciTech 2018, 19, 2048-2057. [CrossRef] [PubMed]

24. Varshney, M.; Morey, T.E.; Shah, D.O.; Flint, J.A.; Moudgil, B.M.; Seubert, C.N.; Dennis, D.M. Pluronicmicroemulsions as nanoreservoirs for extraction of bupivacaine from normal saline. J. Am. Chem. Soc. 2004, 126, 5108-5112. [CrossRef]

25. Brown, W. Dynamic Light Scattering: The Method and Some Applications; Clarendon Press: Bolton, ON, Canada, 1993 ; Volume 49.

26. Rahdar, A.; Almasi-Kashi, M.; Khan, A.M.; Aliahmad, M.; Salimi, A.; Guettari, M.; Kohne, H.E.G. Effect of ion exchange in NaAOT surfactant on droplet size and location of dye within Rhodamine B (RhB)-containing microemulsion at low dye concentration. J. Mol. Liq. 2018, 252, 506-513. [CrossRef] 
27. Rahdar, A.; Amini, N.; Askari, F.; Susan, M.; Hasan, A.B. Dynamic light scattering and zeta potential measurements: Effective techniques to characterize therapeutic nanoparticles. J. Nanoanal. 2019. [CrossRef]

28. Ohkawa, H.; Ohishi, N.; Yagi, K. Assay for lipid peroxides in animal tissues by thiobarbituric acid reaction. Anal. Biochem. 1979, 95, 351-358. [CrossRef]

29. Frisch, M.J.; Trucks, G.W.; Schlegel, H.B.; Scuseria, G.E.; Robb, M.A.; Cheeseman, J.R.; Scalmani, G.; Barone, V.; Mennucci, B.; Nakatsuji, H.; et al. Gaussian 09; Gaussian, Inc.: Wallingford, CT, USA, 2009.

30. Becke, A. The Quantum Theory of Atoms in Molecules: From Solid State to DNA and Drug Design; John Wiley \& Sons: Hoboken, NJ, USA, 2007.

31. Reed, A.E.; Curtiss, L.A.; Weinhold, F. Intermolecular interactions from a natural bond orbital, donor-acceptor viewpoint. Chem. Rev. 1988, 88, 899-926. [CrossRef]

32. Glendening, E.D.; Reed, A.E.; Carpenter, J.E.; Weinhold, F. NBO Version 3.1; Gaussian Inc.: Pittsburgh, PA, USA, 2003.

33. Duan, X.; He, C.; Kron, S.J.; Lin, W. Nanoparticle formulations of cisplatin for cancer therapy. Wiley Interdiscip. Rev. Nanomed. Nanobiotechnol. 2016, 8, 776-791. [CrossRef] [PubMed]

34. Ciarimboli, G. Membrane transporters as mediators of cisplatin side-effects. Anticancer Res. 2014, 34, 547-550. [CrossRef] [PubMed]

35. Guo, S.; Miao, L.; Wang, Y.; Huang, L. Unmodified drug used as a material to construct nanoparticles: Delivery of cisplatin for enhanced anti-cancer therapy. J. Control. Release 2014, 174, 137-142. [CrossRef] [PubMed]

36. Sonoda, A.; Nitta, N.; Ohta, S.; Nitta-Seko, A.; Morikawa, S.; Tabata, Y.; Takahashi, M.; Murata, K. Controlled release and antitumor effect of pluronic F127 mixed with cisplatin in a rabbit model. Cardiovasc. Interv. Radiol. 2010, 33, 135-142. [CrossRef] [PubMed]

37. Sarker, D.K. Engineering of nanoemulsions for drug delivery. Curr. Drug Deliv. 2005, 2, 297-310. [CrossRef] [PubMed]

38. Chen, T.-Y.; Tsai, M.-J.; Chang, L.-C.; Wu, P.-C. Co-Delivery of Cisplatin and Gemcitabine via Viscous Nanoemulsion for Potential Synergistic Intravesical Chemotherapy. Pharmaceutics 2020, 12, 949. [CrossRef] [PubMed]

39. Rahdar, A.; Aliahmad, M.; Hajinezhad, M.R.; Samani, M. Xanthan gum-stabilized nano-ceria: Green chemistry based synthesis, characterization, study of biochemical alterations induced by intraperitoneal doses of nanoparticles in rat. J. Mol. Struct. 2018, 1173, 166-172. [CrossRef]

40. Rahdar, A.; Hajinezhad, M.R.; Hamishekar, H.; Ghamkhari, A.; Kyzas, G.Z. Copolymer/graphene oxide nanocomposites as potential anticancer agents. Polym. Bull. 2020, 1-22. [CrossRef]

41. Rahdar, A.; Taboada, P.; Hajinezhad, M.R.; Barani, M.; Beyzaei, H. Effect of tocopherol on the properties of Pluronic F127 microemulsions: Physico-chemical characterization and in vivo toxicity. J. Mol. Liq. 2019, 277, 624-630. [CrossRef] 